\title{
Health-related quality of life measurement in pediatric clinical practice: An appraisal and precept for future research and application
}

\author{
James W Varni*1, Tasha M Burwinkle² and Mariella M Lane ${ }^{3}$
}

\begin{abstract}
Address: ${ }^{1}$ Department of Pediatrics, College of Medicine, Department of Landscape Architecture and Urban Planning, College of Architecture, Texas A\&M University, 3137 TAMU, College Station, TX 77843-3137 USA, ²Department of Anesthesiology, University of Washington, 1945 NE Pacific Street, Seattle, WA 98195 USA and ${ }^{3}$ Department of Psychology, College of Liberal Arts, Texas A\&M University, College Station, TX 77843 USA

Email: James W Varni* - jvarni@archone.tamu.edu; Tasha M Burwinkle -tmburwinkle@aol.com; Mariella M Lane - mariella@neo.tamu.edu * Corresponding author
\end{abstract}

Published: 16 May 2005

Health and Quality of Life Outcomes 2005, 3:34 doi:10.1 186/1477-7525-3-34

This article is available from: http://www.hqlo.com/content/3/I/34

(c) 2005 Varni et al; licensee BioMed Central Ltd.

This is an Open Access article distributed under the terms of the Creative Commons Attribution License (http://creativecommons.org/licenses/by/2.0), which permits unrestricted use, distribution, and reproduction in any medium, provided the original work is properly cited.

\begin{abstract}
Health-related quality of life (HRQOL) measurement has emerged as an important health outcome in clinical trials, clinical practice improvement strategies, and healthcare services research and evaluation. HRQOL measures are also increasingly proposed for use in clinical practice settings to inform treatment decisions. In settings where HRQOL measures have been utilized with adults, physicians report such measures as useful, some physicians alter their treatment based on patient reports on such instruments, and patients themselves generally feel the instruments to be helpful. However, there is a dearth of studies evaluating the clinical utility of HRQOL measurement in pediatric clinical practice. This paper provides an updated review of the literature and proposes a precept governing the application of pediatric HRQOL measurement in pediatric clinical practice. Utilizing HRQOL measurement in pediatric healthcare settings can facilitate patient-physician communication, improve patient/parent satisfaction, identify hidden morbidities, and assist in clinical decision-making. Demonstrating the utility of pediatric HRQOL measurement in identifying children with the greatest needs, while simultaneously demonstrating the cost advantages of providing timely, targeted interventions to address those needs, may ultimately provide the driving force for incorporating HRQOL measurement in pediatric clinical practice.
\end{abstract}

\section{Review}

The last decade has evidenced a dramatic increase in the development and utilization of health-related quality of life (HRQOL) measures in an effort to improve patient health and determine the value of healthcare services [1]. Most research efforts on HRQOL in medical decisionmaking thus far have focused on measuring patient- reported outcomes (PROs), healthcare utilization, and the incorporation of HRQOL assessments in clinical trials with the goal of identifying group discrimination between treatments. Unfortunately, a dearth of empirical peerreviewed studies exists that have evaluated the clinical utility of HRQOL measurement in pediatric clinical practice. 
The use of HRQOL measurement in clinical practice has focused primarily on adult patients. In settings where HRQOL instruments have been employed with outpatient adults, physicians report that such measures are useful, and that they use PROs to alter treatment. Patients generally perceive the instruments to be helpful in communicating their healthcare needs to their physicians $[2,3]$. Further, a number of position papers have suggested that the routine assessment of HRQOL in clinical practice may facilitate best practices [4,5], with the caveat that the routine use of HRQOL assessment should be considered within the overall framework of evidence-based practice [6].

This paper serves to provide an updated review of the literature and to build a rationale for the incorporation of HRQOL measurement into pediatric clinical practice by evaluating both conceptual arguments for its benefit and existing empirical evidence of outcomes for its use in clinical practice. Since a paucity of data exists on these issues in pediatric clinical care, the adult literature is reviewed and implications for pediatric settings are addressed. Logistical issues related to incorporating such assessment procedures into clinical settings are then examined, and recommendations are made for future research and practice.

\section{Rationale and evidence for the incorporation of HRQOL measurement in clinical practice Facilitation of patient-physician communication}

One potential benefit of incorporating HRQOL assessment into clinical practice is the impact on patient-physician communication [7]. The adult literature supports the idea that both patients and physicians believe HRQOL feedback to physicians assists communication [3,8-11]. For example, patients are often willing to discuss HRQOL with their physicians even when they are not experiencing significant impairments $[8,12]$. Unfortunately, although patients desire to share HRQOL information, physicians are not likely to ask $[8,12-14]$. In fact, research evidence suggests that physician behaviors (e.g., neglecting to ask about HRQOL issues) can impede a patient's willingness to introduce HRQOL concerns, that physicians vary greatly in their ability to elicit important information from patients, and that patients vary in their ability or desire to articulate it $[15,16]$. Patients are, however, generally willing to complete a HRQOL questionnaire at outpatient visits $[8,12]$. In this way, HRQOL measures can be a catalyst for communication in that they can objectively identify areas of concern that can then be discussed at the point of healthcare service.

Unfortunately, there are no randomized controlled studies in the published literature that have examined the impact of pediatric patient self-report or parent proxy- report HRQOL measurement on patient-physician communication. In pediatric practice, communication can be a key issue, as young children may not have the language skills necessary to accurately communicate their symptoms or feelings verbally. For these children, child selfreport HRQOL measures that are sensitive to children's language and cognitive development may indicate problem areas, even those unrelated to the patient's chief complaint, that need to be further explored. In this way, one benefit of standardized HRQOL measurement in pediatric practice is the communication of healthcare needs by the child who may not be able to otherwise accurately report symptoms or other problems with daily functioning.

\section{Improvement in patient satisfaction}

The adult literature suggests that patient satisfaction with medical care has been related to physician discussion of psychosocial topics and active physician elicitation of patient opinion $[17,18]$. Street and colleagues [13] reported that physicians who asked about pain, health perceptions, vitality, and role limitations due to physical problems were evaluated more favorably than physicians who did not. Another study by Brody et al.[19] reported that patients of physicians who received mental health feedback reported more satisfaction with their physician than patients in a control group. In the pediatric literature, no research has examined patient satisfaction and HRQOL assessment in pediatric practice. While it is unclear whether children would respond similarly, parents of pediatric patients are likely to report satisfaction or dissatisfaction with medical care based on their perceptions of their child's HRQOL outcomes as a result of treatment.

\section{Identification of hidden morbidities in pediatric clinical care}

The adult literature has indicated a disparity in physician and patient ratings of health status [20-23]. Physicians frequently underestimate or fail to detect psychosocial and functional disabilities in patients, and often even high levels of psychological distress are undetected and untreated $[22,24-28]$. Studies with adult patients, however, indicate that physicians who receive HRQOL data have significantly higher detection rates for psychological problems [29-32], and for functional and HRQOL impairments $[10,33]$. With this information a physician may be better able to make appropriate referrals and tailor interventions to the specific needs of his/her patients.

Research in pediatric healthcare has also demonstrated the continuing under-identification of psychosocial problems, termed the "new hidden morbidity" [34], in routine pediatric practice $[35,36]$. Given the marked under-detection of these problems by physicians, HRQOL measures can serve as standardized screening instruments for iden- 
tifying physical and psychosocial health concerns from the perspectives of both the child and parent at the point of service that pediatricians might otherwise overlook [37]. However, there are no existing randomized controlled pediatric trials that address this issue. Nevertheless, it seems reasonable to assume that pediatricians are likely to be assisted by standardized HRQOL measurement in the identification of hidden morbidities that might not otherwise be detected.

\section{Impact on clinical decision-making}

In addition to traditional morbidity and mortality outcomes, evidence-based clinical decision-making requires validated patient-reported outcomes, particularly for chronic health conditions [38]. The impact of a HRQOL measurement instrument on clinical decision-making can be tested under the working hypothesis that HRQOL measurement and feedback to physicians must occur at the point of service in order to improve health outcomes [37]. Clinical decision-making may also benefit from a serial screening approach, which can assist with tracking changes in HRQOL over time. This longitudinal monitoring of HRQOL can help physicians evaluate the effectiveness of treatment or monitor disease status and associated symptoms such as pain, fatigue, coughing, wheezing, and the like.

In the adult literature, it has been estimated that up to $52 \%$ of physicians make management decisions (e.g., medication changes, ordering lab tests) on the basis of patient-reported HRQOL $[6,8,39]$. One study found that functional status feedback provided new information for approximately $25 \%$ of patients, resulting in specific clinical management actions by physicians in approximately $40 \%$ of those patients [3]. HRQOL measurement may also assist physicians with the referral process, in that they may be more likely to refer patients to mental health specialists or other health professionals as a result of this information $[8,31]$.

Although these studies with adult patients suggest that improving detection through the use of HRQOL measurement does affect clinical care in various ways, the data regarding changes to clinical practice, after receiving HRQOL feedback, is inconclusive. For example, some adult studies have reported a lack of statistically significant differences between groups of physicians who received HRQOL feedback versus those who did not with regard to changes in prescription of medications, ordering of tests, referrals, or resource utilization [2,6,10,39-41].

The available evidence suggests that simply providing primary care physicians with HRQOL screening information without specific resource and management suggestions may not be sufficient in changing healthcare provider behavior [2,6]. Some physicians even express concern that HRQOL instruments measure some problems they are not prepared to treat; that is, they question the extent to which they could intervene, practically and financially, when certain problems are detected beyond their time and resources to address adequately $[42,43]$. The failure to produce changes in treatment may also be related to physician's limited experience with HRQOL measures or difficulty in translating HRQOL data into specific interventions to improve functioning.

The clinical utility of HRQOL measurement in clinical practice is likely to be enhanced by the availability of measures that are easy to use and interpret, physician education regarding the purpose and utility of HRQOL measurement, and specific management guidelines for deficits in HRQOL $[6,44,45]$. In fact, some investigators have concluded that the provision of targeted recommendations in conjunction with HRQOL scores are needed to yield beneficial effects of HRQOL measurement information on outcomes of care $[8,40,46,47]$. Providing practitioners with easy to use linkage tools (e.g., to appropriate referrals, resources, and evidence-based interventions) may greatly improve the integration of HRQOL data into clinical practice. However, linking HRQOL data to appropriate treatment recommendations, with subsequent improvements in HRQOL outcomes, has not yet been demonstrated empirically in pediatrics.

Thus, while the above studies provide valuable information about the impact of HRQOL on clinical decision making in adult patients, virtually no pediatric studies exist. One study with the Pediatric Quality of Life Inventory $^{\mathrm{TM}}\left(\right.$ PedsQL $\left.{ }^{\mathrm{TM}}\right)$ Generic Core Scales and Rheumatology Module in pediatric rheumatology [48], however, found that for those patients for whom the pediatrician reported that HRQOL measurement at the point of service influenced her clinical decision-making, subsequent HRQOL outcomes demonstrated significant improvement in comparison to patients in which HRQOL assessment was not utilized [37]. Nevertheless, this single empirical study only highlights the need for further research.

\section{Improvement in patient outcomes over time}

A major hypothesized benefit to incorporating HRQOL measurement into routine clinical practice is the potential for identifying symptoms and problems that may result in improved patient outcomes over time. The findings are nevertheless mixed, with some physician-feedback intervention studies in the adult literature demonstrating no significant differences in patient outcomes such as functional status or health status between intervention and control groups $[2,40,44,48,49]$, while other studies has yielded some support for improvement in mental health 
(e.g., depression) $[10,48]$ and role functioning [10] following feedback interventions.

Overall, the results from the adult literature suggest that routine implementation of standardized HRQOL screening may be a necessary but not sufficient condition for enhancing patients' HRQOL. For example, Rubenstein and colleagues [47] reported that providing physicians with patient functional status information in conjunction with management and community resource suggestions resulted in better mental health and social activity scores. Thus, incorporating specific resource management suggestions, such as appropriate referrals and tailored treatments, may enhance the potential potency of HRQOL measurement by providing physicians with variable options to identified problems.

In sum, the adult research on the integration of HRQOL measurement into clinical practice has demonstrated that the provision of HRQOL data to physicians is more likely to impact detection and diagnosis, but is generally not sufficient in changing physicians' management behaviors unless the HRQOL findings are linked to the available resources necessary to improve HRQOL outcomes. The general failure to produce changes in treatment may be related to physician's limited experience with such measures or the difficulty of healthcare professionals in translating HRQOL data into specific interventions to improve functioning. Finally, there may be significant barriers to the implementation of HRQOL measures into clinical practice, as discussed next.

\section{Barriers to incorporating standardized HRQOL measurement in clinical practice}

Barriers such as perceived lack of time, money, and human resources needed to collect, analyze, and interpret HRQOL data, as well as the lack of ongoing computer support for storing and retrieving data, can greatly impede implementation of routine HRQOL measurement in clinical practice $[6,50]$. Thus, while HRQOL measurement logically appears to have potential utility in pediatric clinical practice, there are a number of perceived barriers to use that must be addressed, including that: (1) measures may be perceived as too long, impractical, and difficult to score for a clinic with multiple time constraints; (2) physicians may not be convinced that HRQOL is related to clinical signs and symptoms, which traditionally have been the focus of clinical intervention; (3) implementation of HRQOL measurement may be perceived too costly, requiring additional resources such as staff time and computer scoring systems; (4) implementation of HRQOL measurement is perceived as potentially interfering with clinic operation, and (5) the information provide by HRQOL instruments is perceived to be already availa- ble through conventional testing methods (e.g., semistructured questions about health and symptoms).

\section{Concerns about resources}

Based on their semi-structured interviews of physicians concerning practice-based functional health assessment, McHorney and Bricker [42] found that physicians desired a point-of-service data collection process that did not interrupt the flow of care; perceived barriers included insufficient staff and computing resources, as well as the need for summary output to be able to be immediately implemented. A study in an outpatient oncology clinic addressed several of these issues, reporting that completion, scoring, and printing of patient-reported HRQOL data could be conducted during waiting room time [9]. Additionally, summaries provided to physicians did not lengthen average consultation time, and anecdotally, some physicians expressed the belief that the summary increased their efficiency [9]. Thus, intervention studies comparing duration of physician consultation have found that having access to HRQOL data does not necessarily increase the amount of time spent with patients $[9,10]$.

The application of computer-assisted assessment technology to the measurement of patient self-report and parent proxy-report in pediatric clinical care may reduce a number of the perceived barriers associated with the administration, completion, and scoring of standardized HRQOL instruments, and consequently represents one method for potentially overcoming several barriers to the use of these measures in pediatric practice. Computerassisted HRQOL measurement as a screening methodology may facilitate the identification of areas of concern at the point of service, eliminate a lengthy interview process, and assist with targeting interventions [51-54]. For instance, a one page electronically-generated report can provide a brief summary of symptoms and problem areas for the individual patient on a real time basis, which may influence clinical decision-making at the point of service. This summary report could also generate targeted referral suggestions to facilitate the clinical decision-making process and make suggestions for targeted evidence-based healthcare based on the HRQOL findings.

\section{Attitudinal barriers}

One attitudinal barrier to the incorporation of HRQOL assessment in clinical care is clinicians' views of the relevance and value of this information in patient care. Physicians vary greatly in their degree of willingness to discuss HRQOL issues with patients, and this willingness impacts patients' behavior (e.g., patients do not discuss their HRQOL concerns with their physician unless prompted to do so) $[12,16,55]$. 
Measuring the HRQOL of children in clinical practice may also meet with some resistance by clinicians who feel that the completion of these measures represents too great a burden for children and their parents, particularly children with serious illnesses. Oftentimes, a more qualitative approach is sought, with the belief that such methods are less burdensome and intrusive than standardized quantitative methods [56]. While an understandable concern, similar concerns have been seen in the past in regards to pain measurement in children [57] and HRQOL measurement in children with newly diagnosed cancer [58]. These concerns were met with brief instruments (to reduce respondent burden), developed with focus groups and cognitive interviews (to hear the voices of children and their parents), and by careful attention to the methodological details involved in establishing the reliability and validity of these instruments [59]. Subsequent to the development, field-testing, and documentation of the measurement properties of these standardized quantitative instruments, clinical trials have been conducted targeting pain management and enhancing HRQOL through symptom reduction using these quantitative instruments as outcome measures. Thus, standardized HRQOL instruments have the potential to improve the lives of children by providing the systematic documentation of the efficacy of treatment interventions designed for symptom relief [60]. In palliative care, for instance, standardized measures have the potential to increase the accountability and the quality of the care provided by comparing healthcare institutions or practitioners, and utilizing that information to inform consumers and aid quality improvement efforts [61].

A related attitudinal barrier to use in pediatric clinical practice is the perception by some physicians that HRQOL measures are neither sufficiently associated with nor predictive of subtle changes in physiological parameters $[51,62]$. For example, small-to-medium correlation effect sizes were found between perceived HRQOL and $\mathrm{Hb}_{\mathrm{a} 1 \mathrm{c}}$ in children and adolescents with Type 1 diabetes [63], a finding consistent with the broader literature across diseases [64]. However, as succinctly summarized by McHorney [64]: "QOL scores correlate modestly at best with clinical outcomes. This finding suggests that clinical and human function are relatively independent. It does not imply that one or the other is inherently superior or correct. They simply measure different things, and using both will likely yield more information than any set alone" (p III-58). In fact, the use of physiological parameters to assess disease severity may be problematic, as many health conditions lack physiological markers, and such markers do not often apply across disease categories [65]. Furthermore, a patients' HRQOL may change in the absence of a measured biological change, or vice versa [62]. From this perspective, then, the incorporation of HRQOL measures into clinical practice should not be viewed as proxies for physiological parameters, but rather as a means of providing a more comprehensive evaluation of patient functioning across multiple life domains, particularly when meaningful physiological parameters are not available. This can be the hallmark for providing pediatric comprehensive care; multidimensional assessment leading to targeted interventions based on patient perceived needs.

As medicine shifts to a more patient-centered paradigm [38], willingness to incorporate HRQOL measurement is likely to increase. Physician education can be used to target the aforementioned attitudinal barriers, but Golden [45] notes the inadequacy of continuing medical education in changing physician behaviors and underscores the need for physician leaders who will advocate for and model the use of HRQOL measurement in clinical practice.

Finally, positive experiences with HRQOL measurement may reduce the aforementioned attitudinal barriers. Physicians in intervention studies who have used HRQOL measures report positive attitudes toward HRQOL assessment, expressing beliefs that the HRQOL data were accurate, were useful in clinical practice, could improve patient health status and satisfaction with care, provided new patient information, and facilitated physician-patient communication $[2,8-10,29,39,40,44,46]$. These positive experiences are a necessary but not sufficient condition for change, as detailed later.

\section{Selection of HRQOL instruments for use in pediatric clinical practice}

For HRQOL instruments to be utilized in pediatric clinical practice, they must demonstrate their utility in the clinic setting by addressing the following criteria: (1) they must be brief, yet maintain reliability and validity and provide novel, valuable information; (2) they should be welldesigned both for ease of use by patients/parents and for quick, easy scoring and interpretation; and (3) they must be responsive to meaningful patient change. While a comprehensive review of specific measures and their measurement properties is beyond the scope of this paper, interested readers may find reviews by Eiser \& Morse [67] and Matza [68] helpful. Below we provide a briefly summary of the relative merits of generic and disease-specific measures, child and parent reports, and the measurement properties to consider in selecting an appropriate HRQOL measure for pediatric clinical practice.

\section{Generic and disease-specific HRQOL measures in clinical practice}

There are potential advantages to an integrated modular approach combining the relative merits of generic and disease-specific HRQOL instruments $[59,69,70]$. A generic 
HRQOL measurement instrument allows for screening in healthy populations, enables standardized comparisons across pediatric chronic health conditions, and facilitates benchmarking with healthy populations $[71,72]$. While providing useful benchmarking data for comparisons with healthy children and across different disease groups, generic HRQOL measures may not, however, be as responsive to changes in disease-specific symptoms [73], and typically do not measure specific disease symptoms and treatment side effects of relevance to particular disease groups. In contrast, disease-specific measures (e.g., for asthma, cancer, diabetes, and arthritis) may be more sensitive to specific clinical changes in patients with a particular illness than a generic measure and may be particularly informative for pediatric chronic disease management at the individual patient level. Nevertheless, disease-specific instruments are unable to provide comparisons across diseases, including benchmarking with healthy population norms. Thus, there is an emerging perspective that for pediatric chronic health conditions, both generic and disease-specific HRQOL measures should be administered so as to gain as a more comprehensive evaluation of the patient's HRQOL.

\section{Child self-report versus parent proxy-report in pediatric practice}

Imperfect agreement between self and proxy report, termed cross-informant variance [74], has been consistently documented in the HRQOL assessment of children with chronic health conditions and healthy children [75]. The existence of cross-informant variance and the subjective nature of HRQOL indicate an essential need for reliable and valid child self-report instruments for the broadest age range possible. However, while self-report is considered the standard for measuring perceived HRQOL, there may be circumstances when the child is too young, or too ill or fatigued to complete a HRQOL instrument, and parent proxy-report may be needed in such cases. Further, it is typically parents' perceptions of their children's HRQOL that influences healthcare utilization $[35,76]$. Thus, an instrument should be selected that meets the need to measure the perspectives of both the child and parent since these perspectives may be independently related to healthcare utilization, risk factors, and quality of care.

\section{Measurement properties requisite for individual patient interpretation}

Key instrument properties that are important when HRQOL measurement is employed at the individual patient level include high internal consistency reliability (e.g., alpha .90) and documented responsiveness to change over time as a result of treatment [77]. The establishment of clinically meaningful cut-points to identify atrisk patient status, and the documentation of the magni- tude of score changes representative of clinically meaningful change, are essential measurement properties when using HRQOL instruments in clinical decision-making.

\section{Summary}

The dramatic increase in use of HRQOL measures to evaluate patient outcomes and treatment alternatives reflects an emerging shift in health care toward valuing the patient perspective. However, only a few studies, primarily with adults, have evaluated the utility of HRQOL measurement in clinical practice. This research has demonstrated some support for the benefits of HRQOL measurement in facilitating patient-physician communication, improving patient satisfaction, increasing detection of problems with functioning, informing and altering clinical management, and improving patient outcomes. However, consistency in results is generally lacking, and similar data are virtually nonexistent for pediatric patients. Further, while the provision of HRQOL measurement feedback to physicians is likely to impact detection and diagnosis, it is often insufficient to change physicians' management behaviors (and subsequently improve patient outcomes) unless HRQOL findings are linked to suggestions for specific interventions, including appropriate referral sources.

Routine use of standardized HRQOL instruments in pediatric clinical practice may be impeded by physician attitudinal barriers or concern that completion of these measures represents too great a burden. Further, physicians desire information about the effectiveness of practice-based functional health assessment and are reluctant to routinely use HRQOL measurement if evidence is lacking that it improves patient clinical outcomes. Intervention studies are needed to provide evidence-based demonstration supporting the setting aside of valuable resources needed for the integration of HRQOL measurement in pediatric clinical practice. Intervention studies that provide physicians with targeted recommendations linked to HRQOL data are especially needed.

\section{A precept for future research and practice}

What is the overarching precept or principle that should guide future research in determining the utility of HRQOL measurement in pediatric clinical practice? We propose that while doing the right thing for children is always the foremost principle, the realities of today's healthcare industry mandates that any change to current standard practice demonstrate that the change either does not cost more to the organization, or even more ideally, saves the organization costs in the future.

While cost savings are rarely the sole driving force behind change in pediatric healthcare systems (the corollary to the above is typically true, i.e., cost savings should have no negative impact on care, and ideally improve clinical care 
through greater efficiencies and reduced variances in the provision of care), convincing senior management to implement a change that has upfront costs is challenging at best. Children's Hospitals and pediatric healthcare systems often find themselves struggling to survive during economic downturns. Without clear economic value, as perceived by senior management, or regulatory or legislative mandate, changes in healthcare systems are rarely endorsed.

Thus, we suggest that the overarching precept for determining the likely implementation of HRQOL measurement in pediatric clinical practice requires a win-win circumstance, that is, in doing the right thing for children, the organization actually saves healthcare cost in the future, or at the very least, finds the change "revenue neutral" (i.e., the change pays for itself somehow).

What are the conditions under which such a set of circumstances could be achieved? We believe that nuggets of evidence exist in the literature that portend the set of circumstances above, although only suggestive thus far. Specifically, prospective cohort studies that have demonstrated the utility of HRQOL measurement in predicting future healthcare utilization and costs suggest the necessary but not sufficient condition for the overarching precept above. For example, in the adult literature, lower asthma-specific HRQOL was associated with higher risk of asthma-related emergency department visits or hospitalizations and higher healthcare costs during the subsequent 12 months [78]. In pediatric patients, generic HRQOL (PedsQL ${ }^{\mathrm{TM}}$ ) prospectively accounted for significant variance in healthcare costs at 6,12 , and 24 months [79]. Adjusted regression models that included both HRQOL scores and chronic health condition status accounted for $10.1 \%, 14.4 \%$, and $21.2 \%$ of the variance in healthcare costs at 6, 12, and 24 months. HRQOL and chronic health condition status together defined a 'high risk' group, constituting $8.7 \%$ of the sample and accounting for $37.4 \%$, $59.2 \%$, and $62 \%$ of healthcare costs at 6,12 , and 24 months. The high risk group's per member per month healthcare costs were, on average, 12 times that of other enrollees' at 24 months.

Pediatric risk prediction is of increasing importance for healthcare providers, purchasers, payers, and policy makers. Predicting resource utilization is key to managing defined populations in a prospective payment system and for proactively case-managing those at greatest risk of poor health. If providers knew in advance, for example, at health plan enrollment which children were most likely to become ill, health care resources could be proactively targeted to those children in order to minimize or prevent that morbidity and associated costs. Being able to demonstrate the utility of pediatric HRQOL measurement in identifying children with the greatest needs, while simultaneously demonstrating the cost advantages of providing timely, targeted interventions to address those needs, may ultimately provide the driving force for incorporating HRQOL measurement in pediatric clinical practice.

Thus, the findings above suggest that pediatric HRQOL data can be used to prospectively predict healthcare costs. When combined with chronic health condition status, HRQOL data can identify an at risk group of children as candidates for proactive care coordination. The win-win proposition entails doing the right thing for children when their needs are identified at the point of healthcare contact, with the potential for healthcare cost savings in the future for the healthcare industry. It seems like a precept worth testing in the service of children and society.

\section{List of abbreviations \\ HRQOL Health-Related Quality of Life}

PedsQL ${ }^{\mathrm{TM}}$ Pediatric Quality of Life Inventory ${ }^{\mathrm{TM}}$

\section{Authors' contributions}

All authors contributed to the conceptualization and drafting of the manuscript. All authors read and approved the final manuscript.

\section{References}

I. Fayers PM, Machin D: Quality of life: Assessment, analysis and interpretation New York: Wiley; 2000.

2. Rubenstein LV, Calkins DR, Young RT, Cleary PD, Fink A, Kosecoff J, Jette AM, Davies AR, Delbanco TL, Brook RH: Improving patient function: A randomized trial of functional disability screening. Ann Intern Med 1989, I I I:836-842.

3. Nelson EC, Landgraf JM, Hays RD, Wasson JH, Kirk JW: The functional status of patients: How can it be measured in physicians' offices? Med Care 1990, 28: I III-III26.

4. Jenkinson C: Quality of life measurement: Does it have a place in routine clinical assessment. J Psychosom Res 1994, 38:377-381.

5. Albrecht G: Using subjective health assessments in practice and policy-making. Health Care Anal 1996, 4:284-292.

6. Greehnalgh J, Meadows K: The effectiveness of the use of patient-based measures of health in routine practice in improving the process and outcomes of patient care: A literature review. J Eval Clin Pract 1999, 5:401-416.

7. Theirac SO: Forces motivating the use of health status assessment measures in clinical settings and related research. Med Care 1992, 30(5 Suppl):MSI5-MS22.

8. Wagner AK, Ehrenberg BL, Tran TA, Bungay KM, Cynn DJ, Rogers WH: Patient-based health status measurement in clinical practice: A study of its impact on epilepsy patients' care. Qual Life Res 1997, 6:329-34I.

9. Detmar SB, Aaronson NK: Quality of life assessment in daily clinical oncology practice: A feasibility study. Eur J Cancer 1998, 34:1 $181-1186$.

10. Detmar SB, Muller MJ, Schornagel JH, Wever LD, Aaronson NK: Health-related quality of life assessments and patient-physician communication: a randomized controlled trial. JAMA 2002, 288:3027-3034.

II. Jacobsen PB, Davis K, Cella D: Assessing quality of life in research and clinical practice. Oncology (Huntingt) 2002, 16( 9 Suppl 10): 133-139.

12. Detmar SB, Aaronson NK, Wever LDV, Muller M, Schornagel JH: How are you feeling? Who wants to know? Patients' and oncologists' preferences for discussing health-related quality of life issues. J Clin Oncol 2000, 18:3295-330I. 
13. Street RL, Gold WR, McDowell T: Using health status surveys in medical consultations. Med Care 1994, 32:732-744.

14. Detmar SB, Muller MJ, Wever LDV, Schornagel JH, Aaronson NK: Patient-physician communication during outpatient palliative treatment visits: An observational study. JAMA 200I, 285: |35|-1357.

15. Maguire P, Faulkner A, Booth K, Elliott C, Hillier V: Helping cancer patients disclose their concerns. Eur J Cancer 1996, 32A:78-8I.

16. Beckman HB, Frankel RM: The effect of physician behavior on the collection of data. Ann Intern Med 1984, I 0 I:692-696.

17. Stewart MA: What is a successful doctor-patient interview? A study of interactions and outcomes. Soc Sci Med 1984, 19:167-175.

18. Bertakis KD, Roter D, Putnam SM: The relationship of physician medical interview style to patient satisfaction. J Fam Pract I99|, 32:175-181.

19. Brody DS, Lerman CE, Wolfson HG, Caputo GC: Improvement in physicians' counseling of patients with mental health problems. Arch Intern Med 1990, I 50:993-998.

20. Wartman SA, Morlock LL, Malitz FE, Palm E: Impact of divergent evaluations by physicians and patients of patients' complaints. Public Health Rep 1983, 98: |4|-| 45.

21. Slevin ML, Plant H, Lynch D, Drinkwater J, Gregory WM: Who should measure quality of life, the doctor or the patient? $\mathrm{Br} J$ Cancer 1988, 57:109-112.

22. Calkins DR, Rubenstein LV, Cleary PD, Davies AR, Jette AM, Fink A, Kosecoff J, Young RT, Brook RH, Delbanco TL: Failure of physicians to recognize functional disability in ambulatory patients. Ann Intern Med I99|, I | 4:45 I-454.

23. Nerenz DR, Repasky DP, Whitehouse FW, Kahkonen DM: Ongoing assessment of health status in patients with diabetes mellitus. Med Care 1992, 30((5 Suppl)):MSI I 2-MSI 24.

24. Brody DS: Physician recognition of behavioral, psychological, and social aspects of medical care. Arch Intern Med 1980, I30: | 286- I 289.

25. Steward MA, Buck CW: Physicians' knowledge of and response to patients' problems. Med Care 1977, 1 5:578-585.

26. Nelson E, Conger B, Douglass R, Gephart D, Kirk J, Page R, Clark A, Johnson K, Stone K, Wasson J, Zubkoff M: Functional health status levels of primary care patients. JAMA 1983, 249:333 I-3338.

27. Sprangers MA, Aaronson NK: The role of healthcare providers and significant others in evaluating the quality of life of patients with chronic disease: A review. J Clinic Epidemiol 1992, 45:743-760.

28. Paykel ES, Priest RG: Recognition and management of depression in general practice: Consensus statement. BMJ I992, 305: I 198-1202.

29. Dowrick C: Does testing for depression influence diagnosis or management by general practitioners? Fam Pract 1995, | 2:461-465.

30. Magruder-Habib K, Zung WWK, Feussner JR: Improving physicians' recognition and treatment of depression in general medical care. Med Care 1990, 28:239-250.

31. Mazonson PD, Mathias SD, Fifer SK, Buesching DP, Malek P, Patrick DL: The Mental Health Patient Profile: Does it change primary care physicians' practice patterns? J Am Board Fam Pract 1996, 9:336-345.

32. Gold I, Baraff LJ: Psychiatric screening in the emergency department: Its effects on physician behavior. Ann Emerg Med 1989, 1 8:875-880.

33. Rubenstein LV, McCoy JM, Cope DW, Barrett PA, Hirsch SH, Messer KS, Young RT: Improving patient quality of life with feedback to physicians about functional status. J Gen Intern Med 1995, I0:607-6I4.

34. Costello EJ, Edelbrock C, Costello AJ, Dulkan MK, Burns BJ, Brent D: Psychopathology in pediatric primary care: The new hidden morbidity. Pediatrics 1988, 82:415-424.

35. Varni JW, Setoguchi Y: Screening for behavioral and emotional problems in children and adolescents with congenital or acquired limb deficiencies. Am J Dis Child 1992, I46: 103-107.

36. Wolfe J, Grier HE, Klar N, Levin SB, Ellenbogen JM, Salem-Schatz S, Emanuel EJ, Weeks JC: Symptoms and suffering at the end of life in children with cancer. N Engl J Med 2000, 342:236-333.

37. Varni JW, Seid M, Knight TS, Uzark K, Szer IS: The PedsQL ${ }^{\text {TM }} 4.0$ Generic Core Scales: Sensitivity, responsiveness, and impact on clinical decision-making. J Behav Med 2002, 25:175-193.
38. Sullivan $M$ : The new subjective medicine: Taking the patient's point of view on health care and health. Soc Sci Med 2003, 56:1595-1604.

39. Espallargues M, Vaalderas HM, Alonso J: Provision of feedback on perceived health status to health care professionals. Med Care 2000, 38: I75-186.

40. Kazis LE, Callahan LF, Meenan RF, Pincus T: Health status reports in the care of patients with rheumatoid arthritis. J Clin Epidemiol 1990, 43: I 243-I 253.

41. Gilbody SM, House AO, Sheldon T: Routine administration of health related quality of life (HRQoL) and needs assessment instruments to improve psychological outcome- a systematic review. Psychol Med 2002, 32: I345-I356.

42. McHorney CA, Bricker DE: A qualitative study of patients' and physicians' views about practice-based functional health assessment. Med Care 2002, 40: I I I3- I I 25.

43. Meadows KA, Twidale F, Rogers D: Action research- a model for introducing standardized health assessment in general practice: An exploratory study. J Eval Clin Pract 1998, 4:225-239.

44. Wasson J, Hays R, Rubenstein L, Nelson E, Leaning J, Johnson D, Keller A, Landgraf J, Rosenkrans C: The short term effect of patient health status assessment in a health maintenanace organization. Qual Life Res 1992, I:99-106.

45. Golden WE: Health status measurement: Implementation strategies. Med Care 1992, 30(5 Suppl):MSI87-MSI95.

46. Gilbody SM, House AO, Sheldon TA: Routinely administered questionnaires for depression and anxiety: $A$ systematic review. BM/ 200I, 322:406-409.

47. Rubenstein LV, McCoy JM, Cope DW: Improving patient functional status: $A$ randomized trial of computer-generated resource and management suggestions. Clin Res 1989, 37:80 IA

48. Varni JW, Seid M, Knight TS, Burwinkle TM, Brown J, Szer IS: The PedsQL ${ }^{\text {TM }}$ in pediatric rheumatology: Reliability, validity, and responsiveness of the Pediatric Quality of Life Inventory $^{\mathrm{TM}}$ Generic Core Scales and Rheumatology Module. Arthritis Rheum 2002, 46:714-725.

49. Calkins DR, Rubenstein LV, Cleary PD, Davies AR, Jette AM, Fink A, Kosecoff J, Young RT, Brook RH, Delbanco TL: Functional disability screening of ambulatory patients: A randomized controlled trial in a hospital-based group practice. J Gen Intern Med 1994, 9:590-592.

50. Russak SM, Croft JD, Furst DE, Hohlbauch A, Liang MH, Moreland L, Ofman JJ, Paulus H, Simon LS, Weisman M, Tugwell P, Evidence-Based Medicine Working Groups in Rheumatology: The use of rheumatoid arthritis health-related quality of life patient questionnaires in clinical practice: Lessons learned. Arthritis Rheum 2003, 49:574-584

5I. Carlson L, Speca M, Hagen N, Taenzer P: Computerized quality of life screening in a cancer pain clinic. J Palliat Care 200 I, I 7:46-52.

52. O'Reilly JM, Hubbard ML, Lessler JT, Biemer PP, Turner CF: Audio and video computer assisted self-interviewing: Preliminary tests of new technologies for data collection. J Official Stat 1994, 10:197-214.

53. Turner CF, Rogers SM, Lindberg LD, Pleck JH, Sonenstein FL: Adolescent sexual behavior, drug use, and violence: Increased reporting with computer survey technology. Science 1998, 280:867-873.

54. Couper MP, Rowe B: Evaluation of a computer-assisted selfinterview component in a computer-assisted personal interview survey. Pub Opin Quarterly 1996, 60:89-105.

55. Levinson W, Roter D: Physicians' psychosocial beliefs correlate with their patient communication skills. J Gen Intern Med I995, I 0:375-379.

56. Taylor KM, MacDonald KA, Bezjak A, Ng P, DePetrillo AD: Physicians perspective on quality of life: An exploratory study of oncologists. Qual Life Res 1996, 5:5-14.

57. Varni JW, Thompson KL, Hanson V: The Varni/Thompson Pediatric Pain Questionnaire: I. Chronic musculoskeletal pain in juvenile rheumatoid arthritis. Pain 1987, 28:27-38.

58. Varni JW, Katz ER, Seid M, Quiggins DJL, Friedman-Bender A: The Pediatric Cancer Quality of Life Invenory-32 (PCQL-32): I. Reliability and Validity. Cancer 1998, 82: I I84- I I96.

59. Varni JW, Seid M, Rode CA: The PedsQL ${ }^{\mathrm{TM}}$ : Measurement model for the Pediatric Quality of Life Inventory. Med Care 1999, 37:126-139. 
60. Varni JW, Jacobs JR, Seid M: Treatment adherence as a predictor of health-related quality of life. In Promoting adherence to medical treatment in chronic childhood illness: Concepts, methods, and interventions Edited by: Drotar D. Mahwah, NJ: Erlbaum; 2000:287-305.

61. Teno J, Byock I, Field M: Research agenda for developing measures to examine quality of care and quality of life of patients diagnosed with life-limiting illness. J Pain Symptom Manag 1999, 17:75-82.

62. Frost MH, Bonomi AE, Ferrans CE, Wong GY, Hays RD, Clinical Significance Consensus Meeting Group: Patient, clinician, and population perspectives on determining the clinical significance of quality-of-life scores. Mayo Clin Proc 2002, 77:488-494.

63. Varni JW, Burwinkle TM, Jacobs JR, Gottschalk M, Kaufman F, Jones KL: The PedsQL ${ }^{T M}$ in Type I and Type 2 Diabetes: reliability and validity of the Pediatric Quality of Life Inventory ${ }^{\mathrm{TM}}$ Generic Core Scales and Type I Diabetes Module. Diabetes Care 2003, 26:631-637.

64. McHorney CA: The potential clinical value of quality of life information response to Martin. Med Care 2002, 40(6 Suppl):III56-62.

65. Stein REK, Gortmaker SL, Perrin EC, Perrin JM, Pless IB, Walker DK, Weitzman M: Severity of illness: Concepts and measurements. Lancet 1987, 2:1506-1509.

66. Moore AA, Siu AL, Partridge JM, Hays RD, Adams J: A randomized trial of office-based screening for common problems in older persons. Am J Med 1997, 102:37I-378.

67. Eiser C, Morse R: The measurement of quality of life in children: past and future perspectives. Dev Beh Peds 200I, 22:248-256.

68. Matza LS, Swensen AR, Flood EM, Secnik K, Leidy NK: Assessment of health-related life in children: a review of conceptual, methodological and regulatory issues. Val Health 2004:79-92.

69. Patrick DL, Deyo RA: Generic and disease-specific measures in assessing health status and quality of life. Med Care 1989, 27:S217-S233.

70. Sprangers MAG, Cull A, Bjordal K, Groenvold M, Aaronson NK: The European Organization for Research and Treatment of Cancer approach to quality of life assessment: Guidelines for developing questionnaire modules. Qual Life Res 1993, 2:287-295.

71. Varni JW, Burwinkle TM, Seid M, Skarr D: The PedsQL ${ }^{\text {TM }} 4.0$ as a pediatric population health measure: Feasibility, reliability, and validity. Ambul Pediatr 2003, 3:329-34I.

72. Varni JW, Burwinkle TM, Katz ER, Meeske K, Dickinson P: The PedSQL ${ }^{\mathrm{TM}}$ in pediatric cancer: Reliability and validity of the Pediatric Quality of Life Inventory ${ }^{\mathrm{TM}}$ Generic Core Scales, Multidimensional Fatigue Scale, and Cancer Module. Cancer 2002, 94:2090-2106.

73. Guyatt GH, Feeny DH, Patrick DL: Measuring health-related quality of life: Basic Science Review. Ann Int Med 1993, 70:225-230.

74. Varni JW, Katz ER, Colegrove R, Dolgin M: Adjustment of children with newly diagnosed cancer: Cross-informant variance. J Psychosoc Oncol 1995, 13:23-38.

75. Koot HM, Wallander JL, Eds: Quality of life in child and adolescent illness: Concepts, methods and findings. East Sussex, UK: Brunner-Routledge; 2001.

76. Janicke DM, Finney JW, Riley AW: Children's health care use: A prospective investigation of factors related to care-seeking. Med Care 200I, 39:990-1001.

77. Nunally JC, Bernstein IR: Psychometric Theory. 3rd edition. New York: McGraw-Hill; 1994.

78. Eisner MD, Ackerson LM, Chi F, Kalkbrenner A, Buchner D, Mendoza $G$, Lieu T: Health-related quality of life and future health care utilization for asthma. Ann Asthma Allergy Immunol 2002, 89:46-55.

79. Seid M, Varni JW, Segall D, Kurtin PS: Health-related quality of life as a predictor of pediatric healthcare costs: A two-year prospective cohort analysis. Health Qual Life Outcomes 2004, 2:48.
Publish with Biomed Central and every scientist can read your work free of charge

"BioMed Central will be the most significant development for disseminating the results of biomedical research in our lifetime. "

Sir Paul Nurse, Cancer Research UK

Your research papers will be:

- available free of charge to the entire biomedical community

- peer reviewed and published immediately upon acceptance

- cited in PubMed and archived on PubMed Central

- yours - you keep the copyright

Submit your manuscript here:

http://www.biomedcentral.com/info/publishing_adv.asp
BioMedcentral 